\title{
PERANCANGAN SISTEM INFORMASI TRANSAKSI PENJUALAN PADA BARBERBOX BERBASIS JAVA
}

\author{
Tienneke Andini Prameswari' ${ }^{1}$, Furqoni Yudhistira², Kevin Septianzah ${ }^{3}$ \\ ${ }^{12,3}$ Universitas Indraprasta PGRI \\ Jalan Raya Tengah No 80, Kelurahan Gedong, Pasar Rebo, Jakarta Timur \\ $\underline{1 \text { tiennekeandini@gmail.com, }}, \underline{2 \text { fatihazzam05@gmail.com, }}, \underline{3}$ kevin.septianzah24@gmail.com
}

\begin{abstract}
ABSTRAK
Barbershop merupakan tempat dimana pembeli melakukan perawatan rambut, baik pencukuran rambut maupun pewarnaan rambut serta pencucian rambut. Peneliti menggunakan objek penelitian barbershop Barberbox. Masalah yang terjadi pada Barberbox adalah pelayanan untuk transaksi penjualan masih menggunakan sistem manual yaitu dengan mencatat penjualan pada kertas. Dengan pelayanan yang masih bersifat manual membuat pelayanan menjadi kurang efektif. Oleh karena itu dibangunlah aplikasi transaksi penjualan yang dapat meminimalkan masalah dan memberikan informasi yang dibutuhkan oleh pelanggan maupun pemilik sehingga dapat meningkatkan pelayanan. Aplikasi berbasis desktop ini dibangun menggunakan metode pengembangan sistem waterfall dan pemodelan DFD, dengan bahasa pemrograman Java dengan IDE Netbeans. Database dibuat dengan menggunakan MySLQ. Tujuan penelitian adalah membuat aplikasi yang memudahkan dan mempercepat kerja karyawan untuk memasukan pesanan pembeli dengan komputerisasi. Transaksi penjualan secara otomatis muncul. Semua data otomatis tersimpan didalam database. Dan laporan penjualan terhitung secara otomatis setiap harinya. Hasil penelitian adalah terciptanya Perancangan Sistem Informasi Transaksi Penjualan Pada Barberbox.
\end{abstract}

Kata Kunci: Sistem Informasi Transaksi Penjualan, Barbershop, Java.

\begin{abstract}
Barbershop is a place where buyers do hair care, both haircuts and hair coloring and hair washing. Researchers use the object of research Barbershop Barberbox. The problem that occurs at Barberbox is that the service for sales transactions still uses a manual system, namely by recording sales on paper. With services that are still manual, the service becomes less effective. Therefore, a sales transaction application was built that can minimize problems and provide information needed by customers and owners so that they can improve service. This desktop-based application was built using the waterfall system development method and DFD modeling, using the Java programming language with the Netbeans IDE. The database was created using MySLQ. The purpose of the research is to create an application that makes it easier and faster for employees to enter buyer orders by computerization. Sales transactions automatically appear. All data is automatically stored in the database. And sales reports are calculated automatically every day. The result of the research is the creation of a Sales Transaction Information System Design at Barberbox.
\end{abstract}

Key Word: Sales Transaction Information System, Barbershop, Java.

\section{PENDAHULUAN}

Barbershop merupakan bisnis yang sedang meroket di kalangan para pria masa kini. Barbershop berdiri sekitar abad ke-20 di Amerika Serikat pada tahun 1920 yang memiliki 2 organisasi formal yaitu Associated Master Barbers of America dan National Association of Barber School. Dengan adanya 2 organisasi itu usaha barbershop menjadi berkembang pesat, kecepatan dan efisiensi mencukur menjadi semakin baik (Indra, 2015).

BARBERBOX merupakan suatu bidang usaha yang bergerak dalam pelayanan jasa. Barberbox termasuk dalam kategori salon yang sudah lama berdiri di kota Jakarta, yang memiliki peminat yang cukup banyak. Banyak pelanggan yang datang untuk melakukan perawatan di BARBERBOX. Sehingga transaksi yang terjadi terkadang membuat karyawan salon kewalahan dalam melayani pelanggan dan tidak jarang membuat para pelanggan merasa pelayanannya lamban.

Maka dari itu, sangat dibutuhkannya sebuah sistem yang terkomputerisasi dalam proses pengolahan transaksi. Untuk mengatasi permasalahan tersebut, maka diperlukan sistem informasi transaksi salon yang dapat memberikan informasi data transaksi. Sistem 
informasi ini dapat digunakan sebagai pedoman yang berkaitan dengan pengolahan transaksi pelayanan terhadap pelanggan. Sistem ini diharapkan dapat mempercepat proses penyajian data saat diperlukan dalam menentukan kebijakan. Dengan berdasarkan pada latar belakang tersebut peneliti berupaya untuk mengangkat tentang perencanaan transaksi. Peneliti mengambil judul "Perancangan Sistem Informasi Transaksi Penjualan Pada Barberbox Berbasis Java ".

\section{METODE PENELITIAN}

Dalam pembuatan aplikasi yang terpadu, peneliti menggunakan permodelan SDLC waterfall. Secara harfiah, metode ini berarti air terjun karena memang prosesnya berjalan satu arah dari atas ke bawah. Metode ini pertama kali diutarakan lewat Symposium on Advanced Programming Methods for Digital Computers pada 28-29 Juni 1956 di Washington DC. Hasil dari simposium itu belakangan dibukukuan oleh Pusat Penelitian Maritim Amerika Serikat. Herbert D. Benington menjadi nama yang paling sering dikaitkan dengan pencipta metode pemrogaman ini karena presentasinya pada simposium tahun 1956 itu (Dewi, 2021). Berikut tahap-tahap metode waterfall :

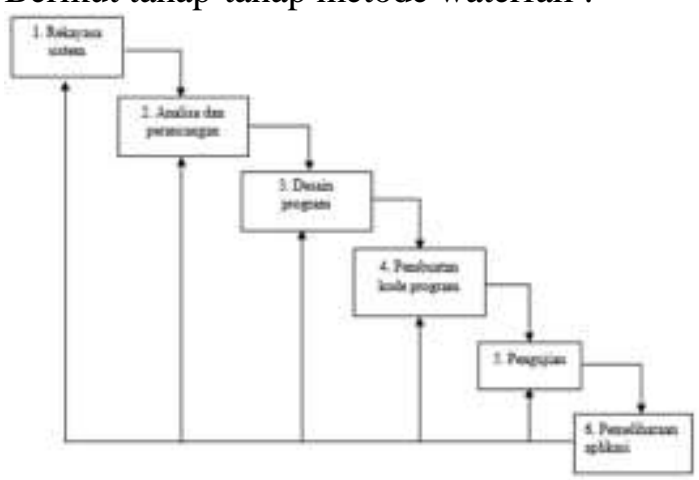

Gambar 1. Metode Waterfall

\section{Requirement Analisys}

Sebelum melakukan pengembangan perangkat lunak, seorang pengembang harus mengetahui dan memahami bagaimana informasi kebutuhan penggguna terhadap sebuah perangkat lunak. Metode pengumpulan informasi ini dapat diperoleh dengan berbagai macam cara diantaranya, diskusi, observasi, survei, wawancara, dan sebagainya. Informasi yang diperoleh kemudian diolah dan dianalisa sehingga didapatkan data atau informasi yang lengkap mengenai spesifikasi kebutuhan pengguna akan perangkat lunak yang akan dikembangkan (Hidayat, 2018).

\section{System and Software Design}

Tahap yang selanjutnya adalah pembuatan desain aplikasi sebelum masuk pada proses coding. Tujuan dari tahap ini, supaya mempunyai gambaran jelas mengenai tampilan dan antarmuka software yang kemudian akan dieksekusi oleh tim programmer.

Untuk proses ini, akan berfokus pada pembangunan struktur data, arsitektur software, perancangan interface, hingga perancangan fungsi internal dan eksternal dari setiap algoritma prosedural. Tim yang mengerjakan tahap ini, biasanya lebih banyak menggunakan UI/UX Designer, atau orang yang memiliki kemampuan dalam bidang desain grafis atau Web Designer (Adani, 2020).

\section{Implementation and Unit Testing}

Tahap implementation and unit testing merupakan tahap pemrograman. Pembuatan perangkat lunak dibagi menjadi modulmodul kecil yang nantinya akan digabungkan dalam tahap berikutnya (Gibran Taufan, 2021). Disamping itu, pada fase ini juga dilakukan pengujian dan pemeriksaan terhadap fungsionalitas modul yang sudah dibuat, apakah sudah memenuhi kriteria yang diinginkan atau belum.

\section{Integration and System Testing}

Setelah seluruh unit atau modul yang dikembangkan dan diuji di tahap implementasi selanjutnya diintegrasikan dalam sistem secara keseluruhan. Setelah proses integrasi selesai, selanjutnya dilakukan pemeriksaan dan pengujian sistem secara keseluruhan untuk mengidentifikasi kemungkinan adanya kegagalan dan kesalahan sistem (Fergie Joanda Kaunang, 2021).

\section{Operation and Maintenance}

Pada tahap terakhir dalam Metode Waterfall, perangkat lunak yang sudah jadi dioperasikan pengguna dan dilakukan pemeliharaan. Pemeliharaan memungkinkan pengembang untuk melakukan perbaikan atas kesalahan yang tidak terdeteksi pada tahap-tahap sebelumnya (Bahjah, 2017). Pemeliharaan 
meliputi perbaikan kesalahan, perbaikan implementasi unit sistem, dan peningkatan dan penyesuaian sistem sesuai dengan kebutuhan (Firman et al., 2016).

\section{HASIL DAN PEMBAHASAN}

Dengan adanya aplikasi transaksi penjualan ini pada Barberbox, menjadikan proses penyimpanan data-data penting pembayawan maupun penginputan data menjadi lebih terstruktur dan lebih baik. Pemodelan menggunakan DFD, yang terdiri dari :

\section{Diagram Konteks Sistem yang Diusulkan}

Diagram konteks adalah diagram tingkat atas, yaitu diagram secara global dari sebuah sistem informasi yang menggambarkan aliran-aliran data ke dalam dan ke luar dari dalam dan luar entitas eksternal (Nilasari, 2014).

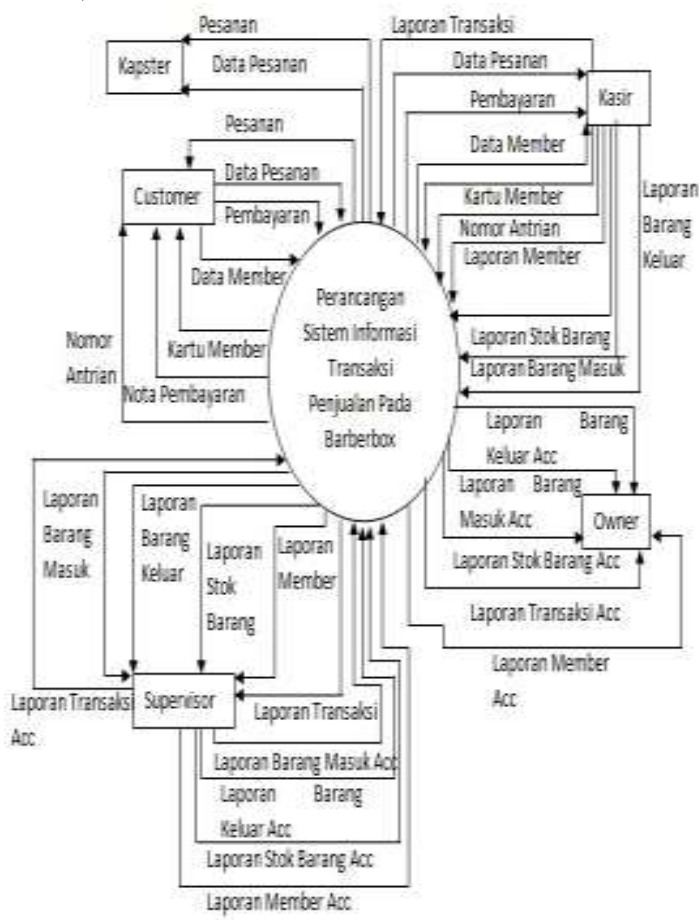

Gambar 2. Diagram Konteks Sistem yang Diusulkan

\section{Entity Relationship Diagram (ERD)}

ERD adalah pemodelan data atau sistem dalam database yang sudah sering digunakan oleh banyak lembaga. Fungsinya ERD adalah untuk memodelkan struktur dan hubungan antar data yang relatif kompleks. Keberadaan sistem ERD sangat penting untuk perusahaan dalam mengelola data yang dimilikinya (Anggun Fergina, 2021).

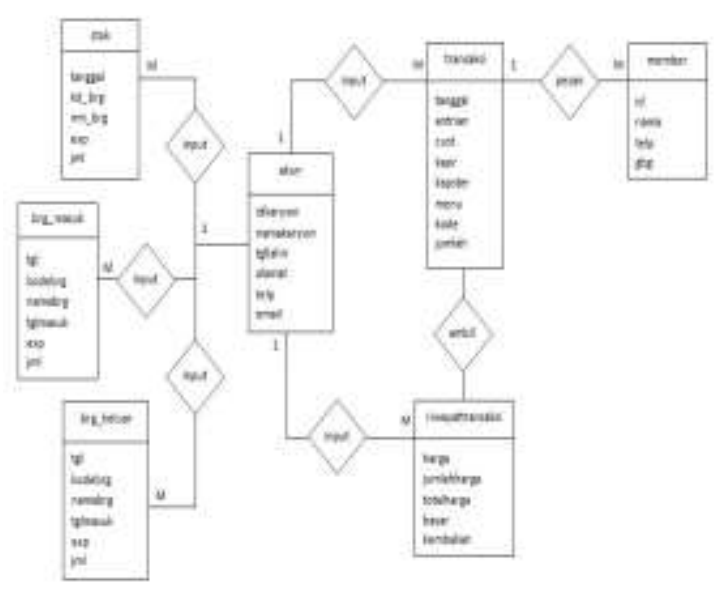

Gambar 3. Entity Relationship Diagram

\section{Tampilan Layar}

Hasil perancangan tampilan layar antarmuka ini adalah bentuk desain aplikasi

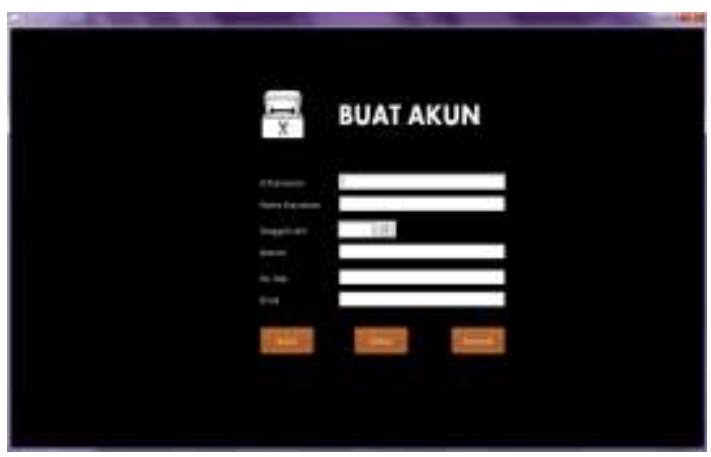

Gambar 4. Form Buat Akun

Menu buat akun digunakan sebagai pendaftaran akun karyawan sebelum kita memasuki menu login.

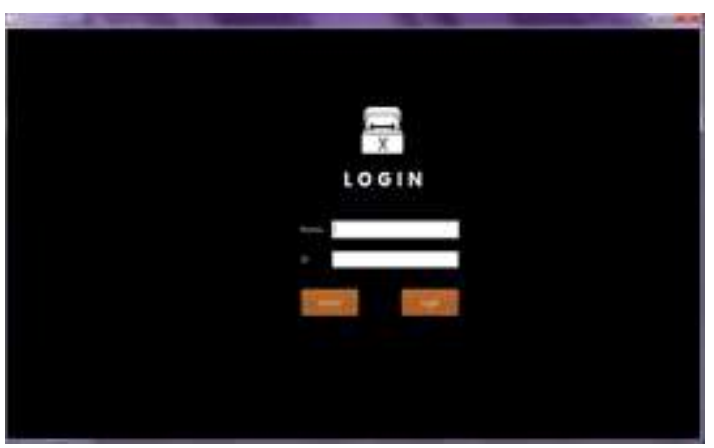

Gambar 5. Form Login

Menu login digunakan sebagai kata kunci sebelum kita memasuki menu utama. Agar tidak sembarangan orang dapat mengakses program ini. 


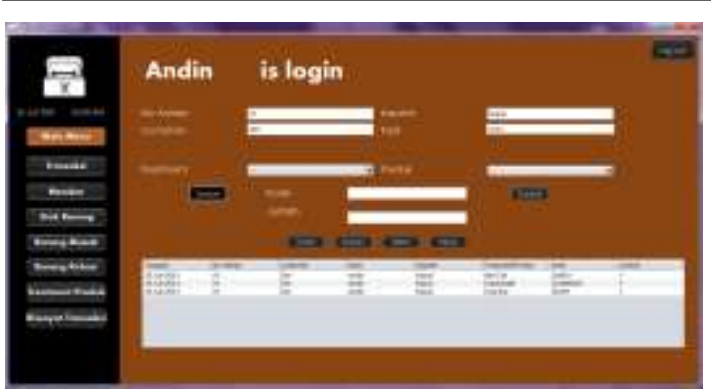

Gambar 6. Menu Utama

Layar diatas menampilkan tampilan menu utama Perancangan Sistem Informasi Transaksi Penjualan Pada Barberbox Menu utama juga digunakan untuk menginput pesanan dan nomor antrian.

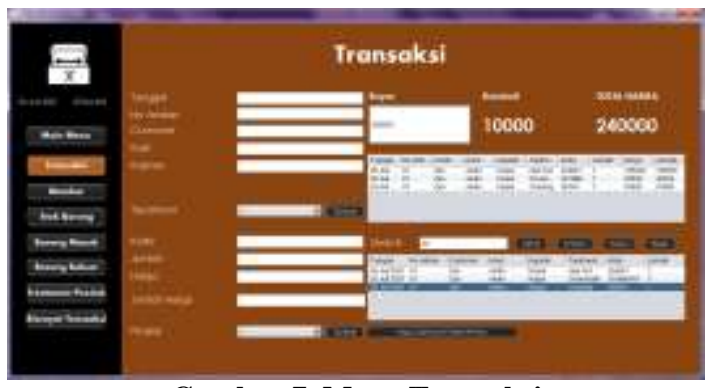

Gambar 7. Menu Transaksi

Tampilan menu transaksi ini digunakan untuk perhitungan jumlah yang harus di bayar customer atas pelayanan yang telah diterima ke bagian kasir.

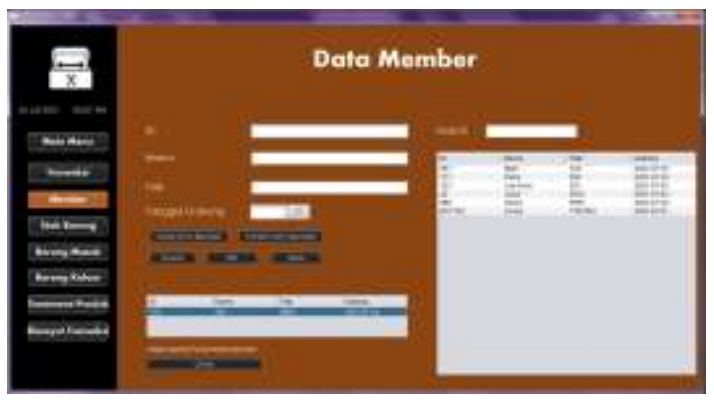

Gambar 8. Menu Data Member

Dalam form member ini digunakan untuk menginput semua data member untuk mendapat sebuah informasi tentang member telah terdaftar di Barberbox yang akan dilakukan proses transaksi pembelian, dan sebagai data yang akan di jadikan acuan untuk mendapatkan diskon.

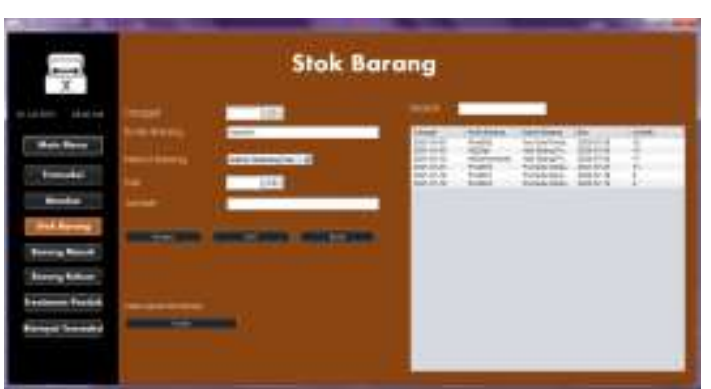

Gambar 9. Menu Stok Barang

Dalam menu stok barang ini digunakan untuk menginput semua data barang/produk untuk mendapat sebuah informasi tentang id barang dan riwayat barang yang tersedia yang akan dilakukan proses transaksi pembelian, dan sebagai data tetap yang akan dijadikan acuan dalam data persediaan barang.

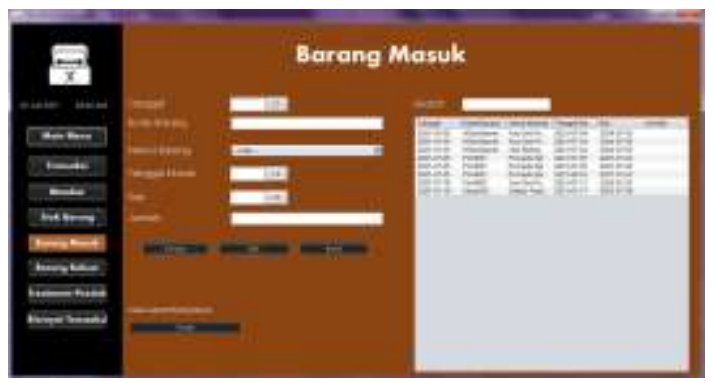

Gambar 10. Menu Barang Masuk

Dalam menu barang masuk ini digunakan untuk menginput semua data barang/produk yang telah masuk dan sebagai data tetap yang akan dijadikan acuan dalam data barang masuk.

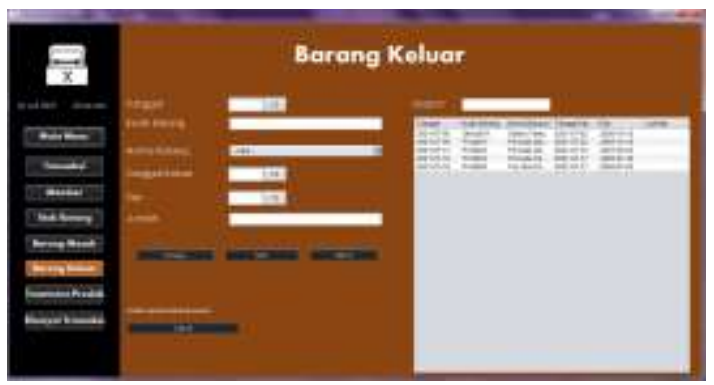

Gambar 11. Menu Barang Keluar

Dalam menu barang keluar ini digunakan untuk menginput semua data barang/produk yang telah terjual dan sebagai data tetap yang akan dijadikan acuan dalam data barang keluar. 


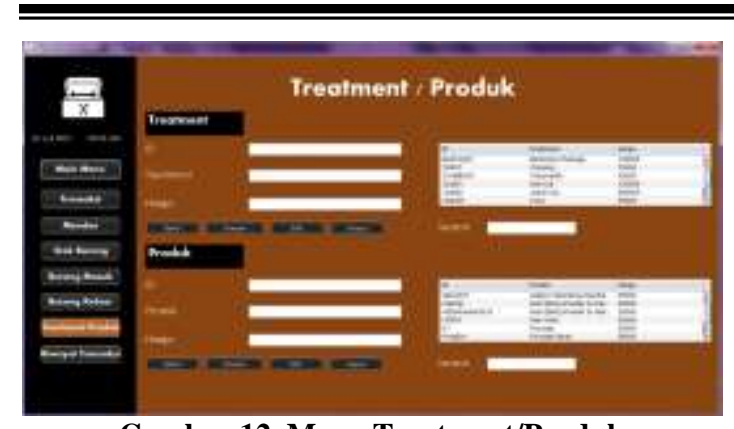

Gambar 12. Menu Treatment/Produk

Dalam menu treatment/produk ini digunakan untuk menginput semua data treatment dan menu untuk mendapat sebuah informasi tentang id dan harga treatment dan produk yang akan dilakukan proses transaksi pembelian.

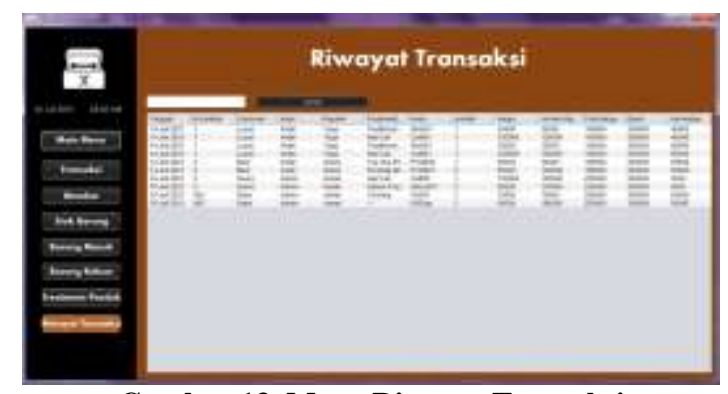

Gambar 13. Menu Riwayat Transaksi

Dalam menu riwayat transaksi ini digunakan untuk menginput semua data transaksi dan sebagai data tetap yang akan dijadikan acuan dalam data barang keluar.

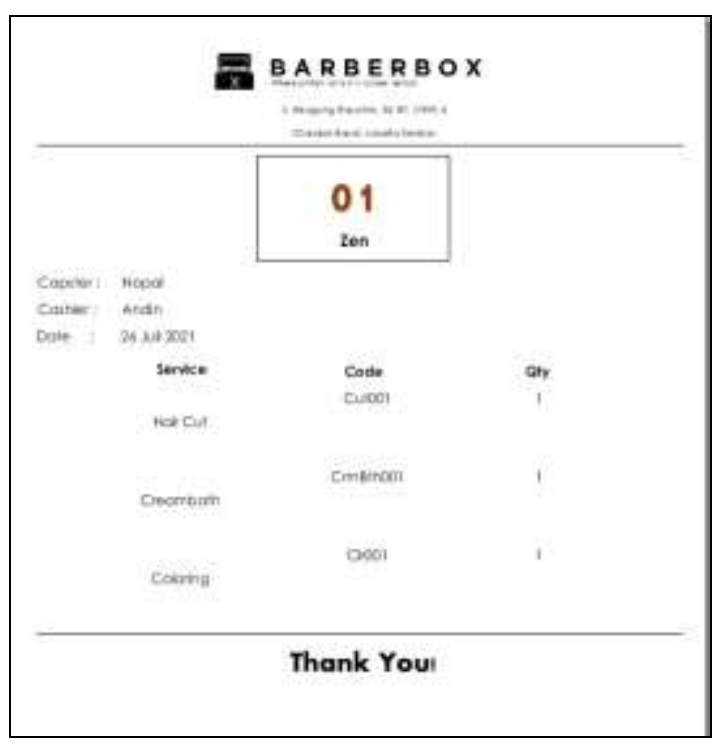

Gambar 14. Nomor Antrian

Nomor antrian ini dapat kita lakukan setelah kita menekan menu utama. Nomor antrian ini berisi nomor antrian dan didalamnya terdapat informasi mengenai data pesanan dari customer.

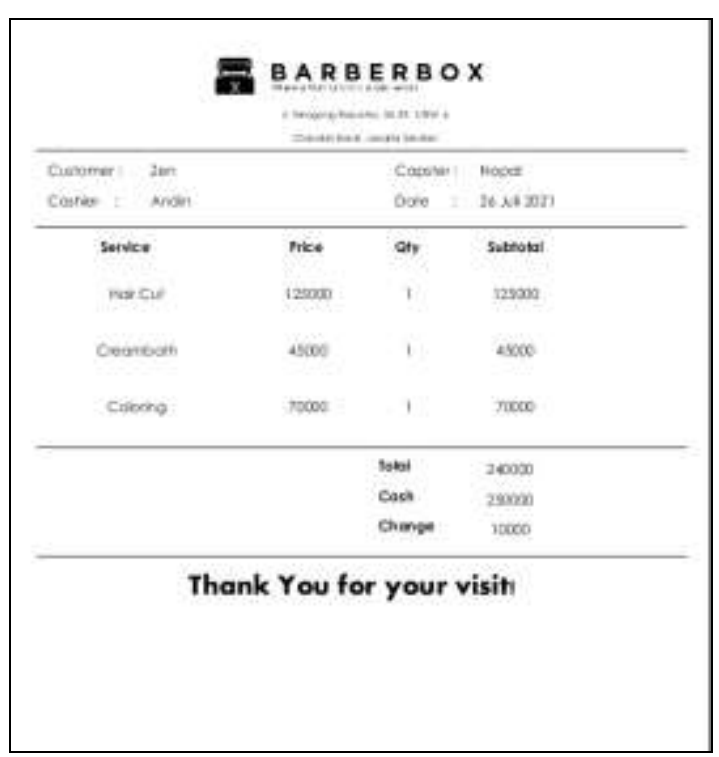

Gambar 15. Nota Pembayaran

Nota pembayaran ini dapat kita lakukan setelah kita menekan menu transaksi. Nota pembayaran ini terdapat informasi mengenai data pesanan, total harga, uang bayar dan kembalian dari customer.

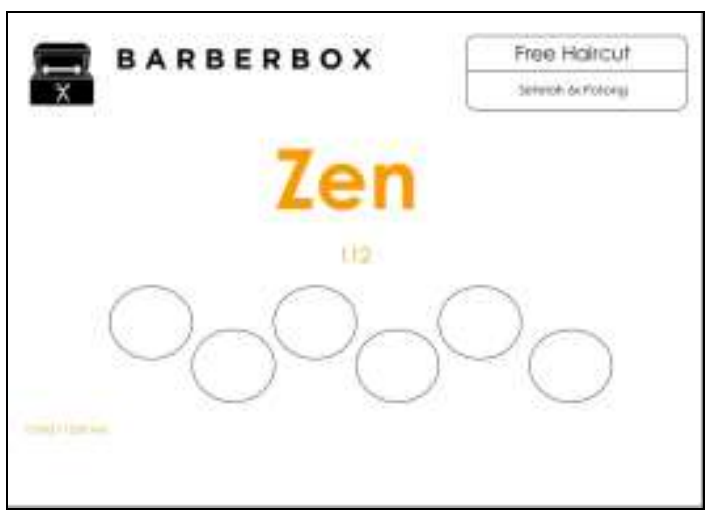

Gambar 16. Kartu Member

Kartu member dapat kita lakukan pada setiap terjadinya proses pendaftaran member, digunakan untuk bukti terdaftarnya customer. 


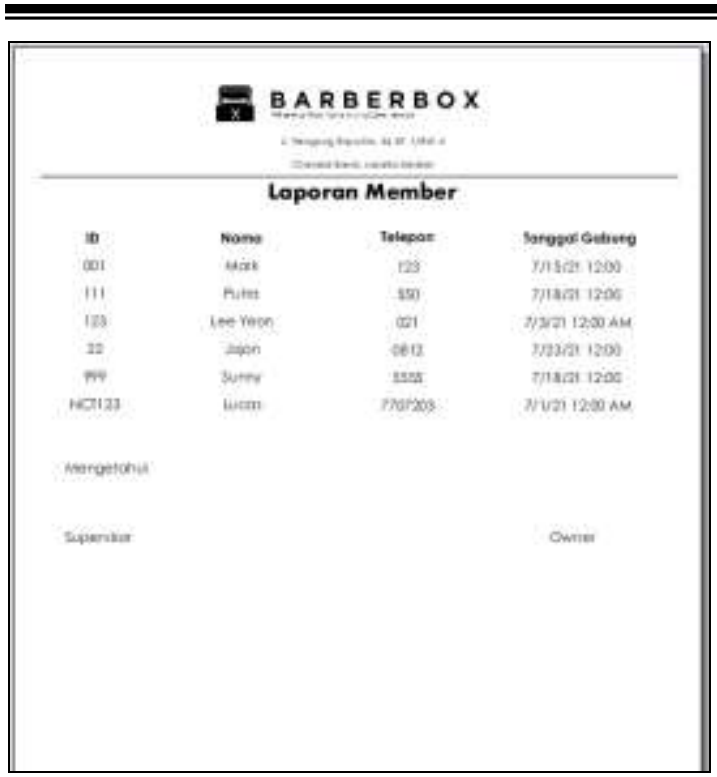

Gambar 17. Laporan Data Member

Rekap laporan ini dapat kita lakukan setelah kita menekan menu member. Rekap laporan ini berisi jumlah data member dan didalamnya terdapat informasi mengenai data member.

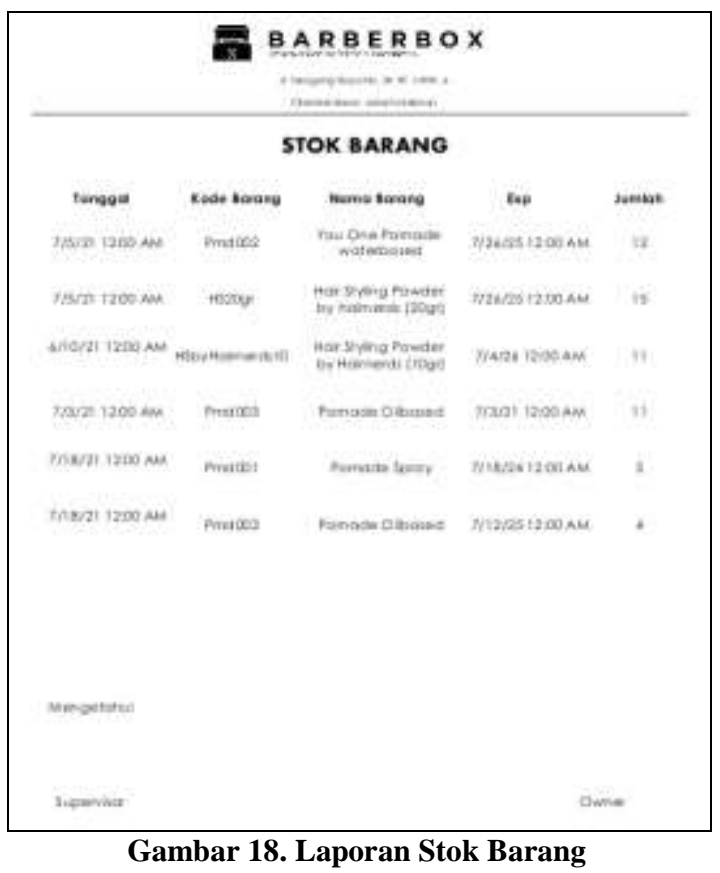

Rekap laporan ini dapat kita lakukan setelah kita menekan menu stok barang. Rekap laporan ini berisi jumlah data persediaan barang yang tersedia.

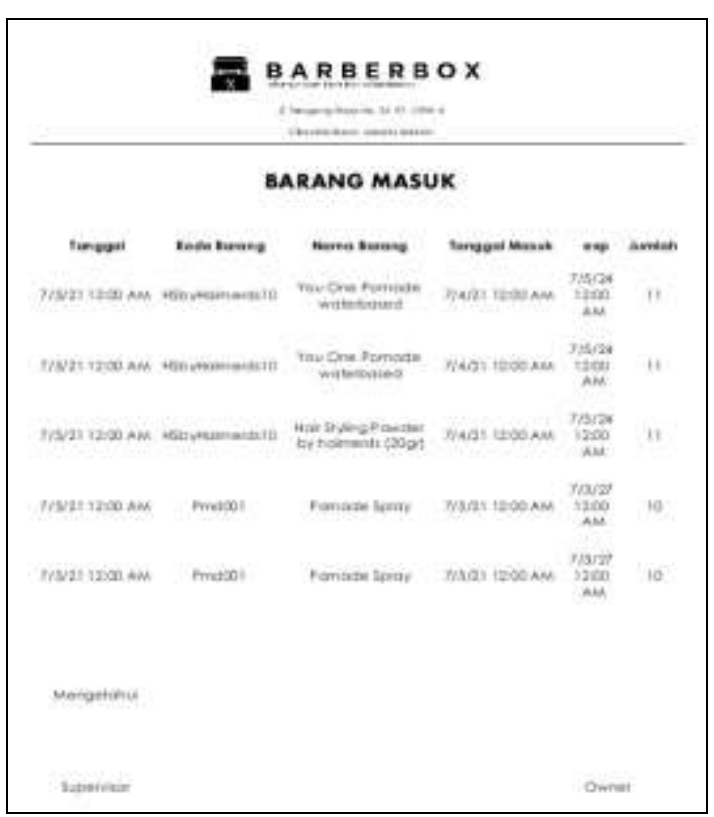

Gambar 19. Laporan Barang Masuk

Rekap laporan ini dapat kita lakukan setelah kita menekan menu barang masuk. Rekap laporan ini berisi jumlah data barang masuk.

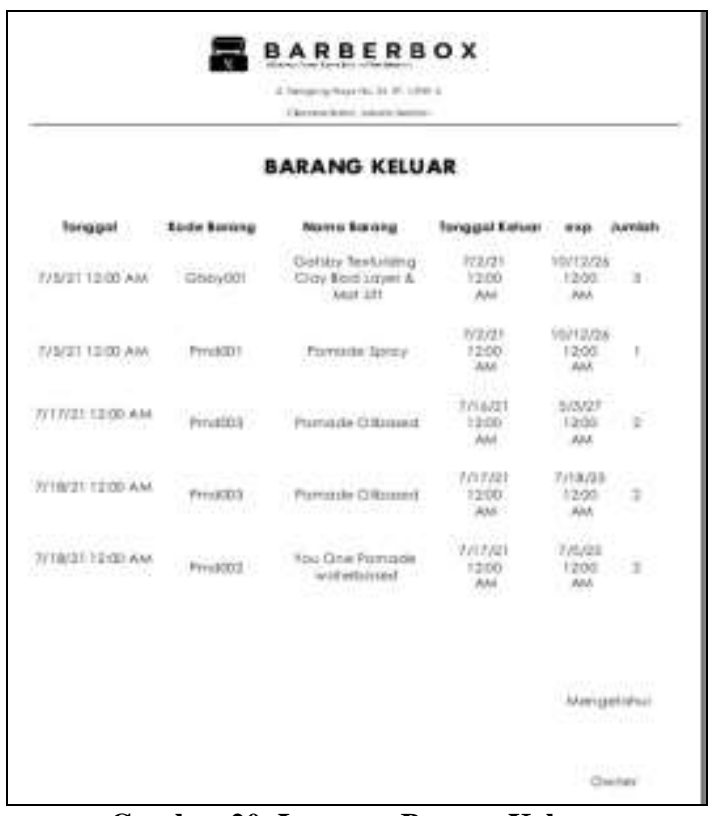

Gambar 20. Laporan Barang Keluar

Rekap laporan ini dapat kita lakukan setelah kita menekan menu barang keluar. Rekap laporan ini berisi jumlah data transaksi keluar barang. 


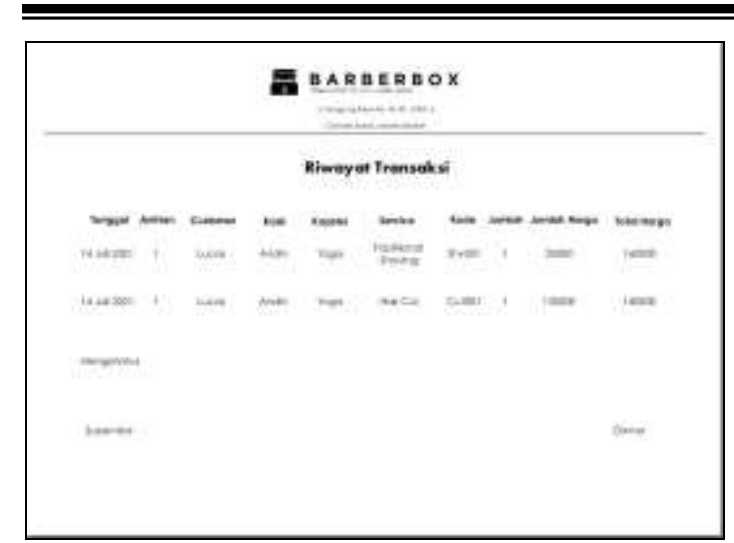

Gambar 21. Laporan Riwayat Transaksi

Rekap laporan ini dapat kita lakukan setelah kita menekan menu riwayat transaksi. Rekap laporan ini berisi jumlah data transaksi yang berhasil dan didalamnya terdapat informasi mengenai data pembayaran oleh customer.

\section{SIMPULAN DAN SARAN}

Dengan adanya aplikasi transaksi penjualan ini pada Barberbox, menjadikan proses penyimpanan data-data penting pembayaran maupun penginputan data menjadi lebih terstruktur dan lebih baik.

Adapun saran untuk sistem tersebut yaitu pembuatan program ini masih dapat dikembangkan seiring berkembangnya spesifikasi kebutuhan pengguna, terutama dalam hal tampilan agar lebih menarik.
DAFTAR PUSTAKA

Adani, M. R. (2020). Tahapan Pengembangan Perangkat Lunak dengan Metode Waterfall. https://www.sekawanmedia.co.id/metod e-waterfall/

Anggun Fergina, D. (2021). Buku Ajar Basis Data. Nusa Putra Press.

BAHJAH. (2017). Metode Waterfall: Definisi, Tahapan, Kelebihan dan Kekurangan.

http://bahjah.blogger.mercubuana.ac.id/ 2017/09/15/metode-waterfall-definisitahapan-kelebihan-dan-kekurangan/

Dewi, N. R. (2021). Metode Waterfall: Pengertian, Tujuan, 6 Tahapan, Dan Contohnya.

https://www.ekrut.com/media/tahapanmetode-waterfall

Fergie Joanda Kaunang, D. (2021). Konsep Teknologi Informasi (R. Watrianthos (ed.)). Yayasan Kita Menulis.

Firman, A., Wowor, H. F., Najoan, X., Teknik, J., Fakultas, E., \& Unsrat, T. (2016). Sistem Informasi Perpustakaan Online Berbasis Web. E-Journal Teknik Elektro Dan Komputer, 5(2), 29-36.

Gibran Taufan, N. M. (2021). Sistem Pemesanan Catering Berbasis Web Pada Pt. Catering Servis Utama. 1(10), 6.

HIDAYAT, C. (2018). Pengertian Metode Waterfall dan Tahap-Tahapnya. https://ranahresearch.com/metodewaterfall/

Indra, G. (2015). Praktek pemotongan rambut pada pria. Praktek Pemotongan Rambut Pada Pria, 4-19. https://elib.unikom.ac.id/files/disk1/706 /jbptunikompp-gdl-galuhindra-3528310-unikom_g-i.pdf

Nilasari. (2014). Diagram Konteks. http://eprints.polsri.ac.id/3123/3/BAB II.pdf 